\title{
Democracias y populismos en América del Sur: Otra perspectiva. \\ Un comentario a «La democracia en América Latina: la alternativa entre populismo y democracia deliberativa» de Osvaldo Guariglia
}

\author{
Democracies and populism in South America: \\ Another perspective. \\ One Response to «Democracy in Latin America: between \\ populism and deliberative democracy» \\ by Osvaldo Guariglia
}

MARTÍN RetAMOZO

Consejo Nacional de Investigaciones Científicas y Técnicas, Argentina

Instituto de Investigaciones en Humanidades y Ciencias Sociales

Universidad Nacional de La Plata

Resumen. En el marco de los debates sobre los procesos políticos actuales en América Latina, este trabajo presenta un análisis crítico del artículo «La democracia en América Latina: la alternativa entre populismo y democracia deliberativa» de O. Guariglia. La lectura del trabajo nos permite mostrar las limitaciones de la argumentación. Por un lado porque no confronta una posición normativa de la democracia deliberativa contra otra concepción normativa que defendería el populismo (en la obra de E. Laclau). Por otro lado, porque las evidencias empíricas sobre los populismos realmente existentes son escasas e imprecisas. Estos límites sin embargo contribuyen al debate porque reavivan la controversia sobre ¿qué democracia? Y habilitan distintas preguntas como ¿Qué conceptos normativos de democracia están presentes en la región? ¿cuáles han sido los alcances de los procesos políticos en América Latina bajo gobiernos «populistas» en el siglo XIX? ¿Qué
Abstract. In the context of discussions on political processes in Latin America, this paper presents a critical analysis about the article «Democracy in Latin America: between populism and deliberative democracy» by $\mathrm{O}$. Guariglia. Reading the work allows us to show the limitations of argumentation. On the one hand because it no confronts a normative position of deliberative democracy against other normative conception would defend populism (in the work of E. Laclau). Furthermore, because the empirical evidence on populism actually existing are few and imprecise. These limits however contribute to the debate because it revived the discussion about what democracy? And open several questions such as: What are normative concepts of democracy in the region? What have been the implications of political processes in Latin America under governments «populist» in the XXI century? Are there real possibilities of democratizing social orders that are crossed 
posibilidades reales hay de democratizar ordenes sociales atravesados por profundas desigualdades como las de los países latinoamericanos?. Las respuestas a estos interrogantes pueden elaborarse desde distintas miradas que aportan pluralidad al debate.

Palabras clave: populismo, democracia, América Latina

\section{Introducción}

El diálogo — se sabe - es constitutivo de la tradición filosófica de occidente. En un célebre poema, Jorge Luis Borges, escribe

Dos griegos están conversando: Sócrates acaso y Parménides.

Conviene que no sepamos nunca sus nombres; la historia, así, será más misteriosa y tranquila.

El tema del diálogo es abstracto. Aluden a veces a mitos, de los que ambos descreen.

Las razones que alegan pueden abundar en falacias y no dan con un fin.

No polemizan. Y no quieren persuadir ni ser persuadidos, no piensan en ganar o en perder.

Están de acuerdo en una sola cosa; saben que la discusión es el no imposible camino para llegar a una verdad.

Libres del mito y de la metáfora, piensan o tratan de pensar.

No sabremos nunca sus nombres.

Esta conversación de dos desconocidos en un lugar de Grecia es el hecho capital de la Historia.

Han olvidado la plegaria y la magia.

Nuestros temas no son abstractos - hablamos de la organización de la polis - y quizás ya no tengamos la confianza en el acceso a la verdad, como aquellos que Sexto Empírico llamó «dogmáticos», pero aun así concebimos la discusión como un camino que contribuye al pensamiento, revisar posiciones y mejorar argumentos, aunque el resulta- by deep inequalities as Latin American? The answers to these questions can be made from different perspectives.

Key words: Populism, democracy, Latin American

do sea fundar un desacuerdo. En un campo académico dominado por estas reglas, el intercambio de argumentos, el diálogo, constituye parte del juego. En este horizonte la recuperación de otras voces presentes en el debate sobre la relación entre populismo y democracia en América Latina no solo aporta a constituir una arena plural, sino que también evoca a los esfuerzos por una filosofía latinoamericana muchas veces invisibilizada por la estructuración de la filosofía dominante (Dussel, 2007). Para los interesados en el proceso político de América Latina, la pluralidad de miradas en un debate indudablemente complejo ofrece la oportunidad de contar con más información y contemplar otras concepciones que también participan de la controversia sobre ese viejo «fantasma que recorre la región», que retorna con la persistencia de los espectros: el populismo.

En este contexto, el reciente artículo de Osvaldo Guariglia (2011) nos invita a revisitar una serie de asuntos ineludibles para pensar los agitados tiempos. La riqueza erudita del trabajo en lo que refiere a la historia de la filosofía es un desafío porque confiere contundencia a una de las más refinadas apuestas desde el liberalismo en América Latina para elaborar críticas a los procesos actuales en países como Venezuela, Bolivia, Ecuador y Argentina. El trabajo de Guariglia es, en el mejor sentido del término, una provocación. Ahora bien, un análisis 
crítico del texto nos ofrece pistas sobre algunos argumentos problemáticos, ilumina las condiciones de enunciación del ensayo y también nos brinda la oportunidad de atisbar perspectivas diferentes que proponen otros modos de interpretar el proceso latinoamericano actual, el populismo y la democracia.

Conviene advertir que este trabajo en particular no se ocupa de discutir las controversias sobre las exégesis de los filósofos clásicos y las tradiciones filosóficas. Mucho más acotada nuestra pretensión se ubica en advertir fundamentalmente dos aspectos que afectan la potencia argumental del ensayo de referencia: el primero radica en un equívoco en el tratamiento de la teoría política del populismo propuesta por Ernesto Laclau; el segundo gira en torno a la debilidad de la evidencia empírica que el autor evoca como sustento de sus afirmaciones. Finalmente el desarrollo crítico de este ensayo nos conducirá a la puesta en cuestión de la tesis de una encrucijada actual en América Latina entre democracia deliberativa y populismo en la que ingresa un aspecto ausente en el artículo pero a nuestro juicio clave para el análisis político (filosófico, teórico y sociológico): las condiciones de posibilidad de democratización de los ordenes sociales en la región, que implica una forma de pensar la relación entre filosofía y política.

La lectura que proponemos muestra que los argumentos vertidos por Guariglia en el trabajo no son suficientes para considerar que populismo y democracia deliberativa son antitéticos. ${ }^{1}$ Por el contrario hay razones y evidencia empírica para, a modo de hipótesis, considerar a los llamados populismos como posibles vehículos democratizadores de sociedades excluyentes y desiguales. Incluso - devolviendo la provocación- al punto de concebirlos como «condición de posibilidad» de la democracia en tanto es/fue la forma histórica en que muchos de los «desaventajados» realmente existentes en América Latina ingresaron tumultuosos a la ciudadanía (condición de la democracia). ${ }^{2}$ De este modo estamos tentados a realizar una referencia tomando la estructura de un conocido chiste de Marx (Groucho) y ante la pregunta «ipopulismo o democracia?» responder «Si, por favor!», es decir, negándonos a la dicotomía estipulada en el interrogante. Pero vayamos por partes.

\section{Es el populismo...}

Es cierto, como se ha afirmado hasta el hartazgo, que «populismo» es un término maldito. La teoría política y las ciencias sociales han reflexionado sobre la polisemia del concepto así como su status epistémico. ${ }^{3}$ En efecto, no es solo que populismo tiene distintos referentes, sino que opera para nominar diferentes fenómenos. Se utiliza - tanto en el debate público como en el académico- el vocablo populismo para designar a líderes, a los que se cataloga de demagogos, autoritarios, personalistas o decisionistas. Se refiere como populistas a determinados movimientos tildados de irracionales, protagonizado por «masas», pasionales y policlasistas. Pero también se identifica a ciertas políticas como populistas, cuando ellas generan intervenciones en el funcionamiento del mercado, políticas públicas de transferencias de ingresos (condicionados o no condicionados), estatizaciones de empresas o nacionalizaciones de recursos. También hay ideologías calificadas como populistas, las cuales sustentarían una visión orgánica de pueblo por sobre los individuos y las clases, combinaciones de tradicionalismo con antiintelectualismo o antimodernismo y antielitismo. En otros trabajos el populismo ha sido calificado como un 
régimen político caracterizado por una ciudadanía de baja intensidad, democracia delegativa y con ausencia de equilibrio o transparencia en el ejercicio de los poderes públicos. Este uso equívoco del concepto frecuente en el campo de los estudios políticos se hace presente en el texto de Guariglia quién además suma el de «neopopulismo» para hablar de los actuales regímenes. Frente a esta situación es imperioso, si se desea utilizar el concepto, precisarlo y evitar superponer dimensiones de análisis y campos conceptuales. Aunque no podamos elucidar la esencia del «populismo» — sencillamente porque no existe tal cosa- al menos podemos definir los alcances que cada uno le concede al término.

Podríamos considerar que tampoco sobre el concepto de «democracia» hay un acuerdo unánime (liberal, republicana, deliberativa, participativa, directa, representativa, delegativa, comunitaria, socialista, son algunos de los adjetivos presentes en el debate sobre democracia), no obstante el artículo de Guariglia es preciso a la hora de posicionarse en una tradición conceptual-normativa sobre el tópico. ${ }^{4}$ Así, mientras que el concepto de populismo queda confundido en múltiples referencias que pueden conducir a equívocos e imprecisiones en el análisis, el término democracia —más allá que podamos discutir tanto la interpretación de Aristóteles como su validez normativa para las democracias actuales - es definido con cierta precisión. Esto contrasta con la escasa atención al concepto de populismo - como categoría - lo que impide refinar los argumentos a la vez que ofrece un espantapájaros al alcance de cualquier crítica normativa. ${ }^{5}$ En consecuencia una de las primeras tareas es precisar el concepto de populismo.

No podemos entrar en una discusión sobre los diferentes sentidos del populis- mo, tanto en sus definiciones teóricas como en el uso que del término se ha realizado para dar cuenta de los procesos de América Latina (en gran medida diferentes de los usos en el mundo europeo). Hay una serie de trabajos de suma relevancia que si bien no agotan la discusión al menos ofrecen un orden (Weyland, 2001, Wayland, De la Torre, Aboy Carlés, Ibarra, 2004, et. al.). Por nuestra parte utilizaremos como piedra de toque la teoría del populismo propuesta por Ernesto Laclau debido a tres razones: primero porque es la referencia que Guariglia utiliza para fustigar como defensor de un «populismo autoritario»(sic) (junto con Chantal Mouffe); segundo porque esta teoría se ha constituido como uno de los insumos analíticos para pensar el proceso de la última larga década que otros autores han denominado «el giro a la izquierda en América Latina» (Castañeda, 2006; Arditi, 2009); tercero porque precisamente Laclau busca desde su teoría sortear los problemas de la multidimensionalidad superpuesta en el concepto de populismo al definirlo como una «lógica» (de la) política.

La teoría del populismo de Laclau no se ubica — para seguir con la distinción aristotélica - ni en un terreno normativo ni apunta a caracterizar procesos históricos, sino que se concibe como una categoría para el análisis político, puntualmente para el estudio de los modos de constitución de las identidades políticas. Laclau argumenta con claridad «el concepto de populismo que estoy proponiendo es estrictamente formal, ya que todos sus rasgos definitorios están relacionados exclusivamente a un modo de articulación específico - la prevalencia de la lógica equivalencial por sobre la lógica diferencial - independientemente de los contenidos reales que se articulan»" (Laclau 2009:65), por lo tanto es imposible adscribirle a priori una orientación 
al populismo. El populismo como una lógica política (que opera en el nivel ontológico) puede articular diferentes contenidos desde demandas aristotélicamente democráticas (por la isonomía y elehutería) como demanda de mujeres víctimas de violencia de género, indígenas desplazados de sus territorios ancestrales y obreros en reclamo por sus condiciones laborales (las que podríamos considerar democráticas) hasta demandas que consideraríamos autoritarias como aquellas xenófobas, sexistas, homofóbicas, elitistas (expulsar a los inmigrantes, instalar la educación religiosa obligatoria y la prohibición de la homosexualidad). La formalidad de la teoría no permite pronunciarnos ex ante sobre los contenidos de la demandas, esto es algo que debe determinarse a través del estudio sociopolítico. ${ }^{6}$ Por lo tanto en la teoría de Ernesto Laclau (2004) es lógicamente imposible imputarle al populismo un contenido (sea democrático o autoritario) sin considerar al menos tres aspectos: el contenido de las demandas, los modos en que se articulan (y su presencia en el espacio público) y el contexto histórico (sistema o totalidad vigente) en que tales demandas surgen.

Populismo designa para Laclau una lógica política que describe como las demandas insatisfechas en un orden social son gestionadas y factibles de ingresar en un proceso de articulación en el que se producen encuentros de posiciones subjetivas disímiles. En esta dimensión las críticas pertinentes a la teoría de Laclau se posicionan en el extremo opuesto a la acusación del autor. Por un lado, en tanto el populismo es una lógica de resistencia política de los de abajo (de los que tienen demandas insatisfechas. ${ }^{7}$ ) nos habla de la gramática de construcción de los sujetos políticos. En consecuencia se replantea la pregunta por los procesos políticos que produjeron articulaciones de demandas negadas y que accedieron mediante elecciones libres al gobierno del Estado [precisamente dando respuestas a los sectores sociales que Guariglia denomina «masas motivadas por las expectativas salvíficas» (2011:65)]. Si se lo prefiere en otros términos, la pregunta es por los llamados «gobiernos populistas».

En tanto populismo designa el modo en que se articulan demandas no satisfechas por el orden, la existencia de sectores sociales cuyas demandas no son incluidas (como en América Latina, la región más desigual del planeta) es condición de posibilidad del populismo. La negación sistemática a las demandas por parte del orden vigente produce un campo común de reconocimiento $\mathrm{y}$, en ese acto, se establece una frontera interna en la sociedad para movilizarse enfrentando a aquellos sectores que se considera responsables de la situación. En tal sentido es cierto, como dice Guariglia, que el populismo latinoamericano tiene aspectos que lo ubican en una tradición del republicanismo popular y que parte de situaciones de desigualdad en un contexto de descrédito de la democracia liberal tal como lo identificaron de distinta forma Canovan (1999) y Arditi (2004). El aporte de Laclau radica justamente en proporcionar elementos para pensar una lógica de construcción política presente en América del Sur que politiza situaciones de subordinación producidas por el orden socio-histórico colonial y neoliberal.

Por otro lado, la discusión sobre el déficit normativo en la teoría de Laclau ha sido objeto de diversas críticas (Critchley, 2008). La teoría sirve para analizar las formas de construcción de sujetos políticos pero nada nos dice sobre qué proyectos que incorporan la lógica populista son preferibles. El populismo como categoría teórica es independiente de los contenidos ónticos articula- 
dos y es tarea de la investigación empírica determinar los alcances de las experiencias que privilegian la lógica populista. Una crítica normativa a la teoría del populismo de Laclau es imposible puesto que, como han señalado varios autores, uno de los problemas de su enfoque es la ausencia de este punto en relación a la formalidad de su propuesta. Para algunos autores si hay un lugar en el que se desarrollan aspectos normativos es en la escasamente desarrollada concepción de «democracia radical».

\section{Historia y política en América del Sur.}

Lo expuesto en la sección anterior nos conduce a comentar un segundo aspecto del artículo: la ahistoricidad de la reflexión y las imprecisiones en el uso de las fuentes que debilitan los argumentos ofrecidos por el autor. La dimensión histórico-concreta es relevante en tanto la perspectiva normativa aristotélica se utiliza para juzgar procesos políticos actuales y encontramos en el trabajo afirmaciones empíricas. Precisar los alcances de la experiencia política en algunos países de América Latina es, por lo tanto, fundamental para evitar la confusión por parte de lectores no latinoamericanos o poco familiarizados con las dinámicas políticas actuales presentes en la región. Cuatro son los «casos» de referencia que a veces explícita y otras implícitamente hace el autor, a saber: Venezuela, Bolivia, Ecuador, y Argentina, ${ }^{8}$ analicemos pues cuáles son las afirmaciones y las evidencias que se nos ofrece sobre los procesos tildados de populistas.

Uno de los mayores peligros del populismo, nos dice Guariglia, es la tentación de las «masas» movilizadas de confiar en líderes que se colocan por encima de las instituciones, incluso de las normativas internacionales, la referencia que prueba tal autoritarismo se encontraría en un trabajo de Carlos de la Torre. Sin embargo, una lectura del trabajo referido nos muestra que De la Torre, sin ser un defensor del populismo e identificando rasgos potencialmente autoritarios, también reconoce el importante impacto del populismo en la ampliación de la democracia restringida de la región andina. Permítasenos citar algunos fragmentos:

«El gobierno de Chávez ha creado varias instancias para institucionalizar la democracia participativa y protagónica como son los círculos bolivarianos, los consejos comunales y las asambleas ciudadanas. Los círculos bolivarianos se establecieron para organizar el apoyo a Chávez y para hacer efectiva las formas de democracia participativa y protagónica. Funcionaron entre el 2001 y el 2004 y tuvieron un rol importante en las protestas en contra del golpe de Estado contra Chávez en el 2002. Si bien es indudable que los círculos han incrementado la participación popular y han politizado a sectores previamente excluidos, no están basados en la "clase de autonomía que la democracia requiere"”. ${ }^{9}$ (De la Torre, 2009: 27).

\section{Sobre Bolivia, De la Torre expresa:}

«La noción que la democracia liberal expresa formas coloniales de poder y de conocimiento ha sido articulada con más fuerza por intelectuales bolivianos. Estos académicos argumentan que en Bolivia además de la democracia liberal existe la democracia comunitaria que está presente en los alluys aymaras y quechuas, y que se manifestó en las ciudades con fuerte presencia indígena durante las rebeliones del 2000 y del 2003. La democracia comunitaria se basa en los principios de reciprocidad, en la deliberación de todos en las decisiones, en la obligación de asumir cargos de poder y responsabilidad y en la rotación de los cargos. En estas formas de democracia los derechos individuales son parte de los fines colectivos y no se diferencian las esferas legislativa, ejecutiva y judicial. La democracia comunal se basa en la participación plena de sus miembros y en el 
acatamiento obligatorio de las decisiones consensuadas. A diferencia de la representación liberal basada en la delegación, en las formas de representación comunal el representante «solamente expresa y cumple lo que deliberó la colectividad». (De la Torre, 2009:28, las cursivas nos pertenecen en tanto marcan el elemento deliberativo de la democracia comunitaria boliviana).

En efecto, De la Torre señala que el populismo no respeta cabalmente las normas y procedimientos de la democracia liberal y rechaza ciertas mediaciones de la democracia representativa, es decir, produce una tensión con un tipo de democracia, no la democracia tout court. Además destaca la incorporación que hacen algunos regímenes populistas de mecanismos de democracia participativa novedosas para los acotados escenarios en que se desarrollaron las ciudadanías políticas de sectores subalternos en países de América del Sur. En este sentido podemos mencionar que en Ecuador también se reglamentaron algunos mecanismos de democracia directa y en concreto existieron seis consultas populares vinculantes en las que las propuestas gubernamentales obtuvieron más del $60 \%$ del electorado a su favor.

Por su parte frente a la acusación de que el populismo promueve a líderes que se ponen por sobre la constitución y los tratados internacionales en materia de Derechos Humanos es necesario precisar que textos constitucionales de Venezuela, Ecuador y Bolivia (sancionados por «populistas») responden a las normativas internacionales en el plano de los Derechos Humanos. En la Constitución Bolivariana el concepto «derechos humanos» aparece 40 veces, mientras que en la Constitución de Ecuador del 2008 aparece 28 veces. Además la Carta Magna ecuatoriana crea los Consejos Nacionales de Igualdad, cuya función es la siguiente:
Art. 156. Los consejos nacionales para la igualdad son órganos responsables de asegurar la plena vigencia y el ejercicio de los derechos consagrados en la Constitución y en los instrumentos internacionales de derechos humanos. Los consejos ejercerán atribuciones en la formulación, transversalización, observancia, seguimiento y evaluación de las políticas públicas relacionadas con las temáticas de género, étnicas, generacionales, interculturales, y de discapacidades y movilidad humana, de acuerdo con la ley. Para el cumplimiento de sus fines se coordinarán con las entidades rectoras y ejecutoras y con los organismos especializados en la protección de derechos en todos los niveles de gobierno.

En su artículo 280, la constitución de Venezuela consagra que la «Defensoría del Pueblo tiene a su cargo la promoción, defensa y vigilancia de los derechos y garantías establecidos en esta Constitución y los tratados internacionales sobre derechos humanos, además de los intereses legítimos, colectivos y difusos, de los ciudadanos»».

En el capítulo IV de este segundo título ( De los derechos políticos y del referendo popular»), dice en el artículo 62 :

«Todos los ciudadanos y ciudadanas tienen el derecho de participar libremente en los asuntos públicos, directamente o por medio de sus representantes elegidos o elegidas. La participación del pueblo en la formación, ejecución y control de la gestión pública es el medio necesario para lograr el protagonismo que garantice su completo desarrollo, tanto individual como colectivo».

El artículo 70 «Son medios de participación y protagonismo del pueblo en el ejercicio de su soberanía, en lo político: la elección de cargos públicos, el referendo, la consulta popular, la revocatoria del mandato, la iniciativa legislativa, constitucional y constituyente, el cabildo abierto y la asamblea de ciudadanos y ciudadanas cuyas decisiones serán de carácter vinculante».

En la constitución del Ecuador hay que tener en cuenta la instauración del 
Quinto Poder del Estado que se materializa en el denominado "Consejo de Participación Ciudadana y Control Social» y sería ejercido por la ciudadanía. Estaría conformado por individuos que no hubieran participado en política con anterioridad, cuyas funciones residirían en ejercer el control de rendición de cuentas por parte de las autoridades políticas. ${ }^{10}$

Enrique Dussel (2006) argumenta que estas reformas son aportes y desafíos para la filosofía política establecida porque introduce una novedad: el Poder Ciudadano, que amplía la composición de los poderes de la república tal como se ha considerado tradicionalmente desde Montesquieu. En consecuencia además del Poder Legislativo y el Poder Ejecutivo, elegidos por el voto popular y el Poder Judicial conformado mediante otros mecanismos, la constitución de la República Bolivariana de Venezuela propone un cuarto poder y un quinto poder (el Poder Electoral).

En la constitución política del Estado plurinacional de Bolivia - sancionada bajo el gobierno de Evo Moralesleemos en el artículo 14 inciso III «El Estado garantiza a todas las personas y colectividades, sin discriminación alguna, el libre y eficaz ejercicio de los derechos establecidos en esta Constitución, las leyes y los tratados internacionales de derechos humanos». La constitución ecuatoriana, a su vez, establece en el artículo 11 inciso III «Los derechos y garantías establecidos en la Constitución y en los instrumentos internacionales de derechos humanos serán de directa e inmediata aplicación por y ante cualquier servidora o servidor público, administrativo o judicial, de oficio o a petición de parte».

Por supuesto que la normativa constitucional no garantiza su cabal cumplimiento ni asegura contra la violación de facto de los principios allí expresados y/o los tratados internacionales pero en la acusación de liderazgos temerarios que avasallan las leyes nacionales, la división de poderes y el derecho internacional debe ser tratado con rigor metodológico. No fueron las democracias «atrasadas» de América del Sur las que invadieron países soberanos, suspendieron libertades individuales y legalizaron cárceles como las de Guantánamo, intervinieron en golpes de Estado y desconocieron las resoluciones de la Organización de Naciones Unidas.

Dejando de lado la cuestión normativa/legal de los derechos humanos hay claras políticas de parte de estos gobiernos en su defensa. En Ecuador Rafael Correa creó la Comisión de la Verdad para investigar casos de violación a los derechos humanos, mientras que los gobiernos de Néstor y Cristina Fernández de Kirchner impulsaron una política de derechos humanos reivindicada por organizaciones como Madres de Plaza de Mayo y Abuelas de Plaza de Mayo, que llevó a la anulación de las leyes que promovieron la impunidad de crímenes de lesa humanidad sancionadas bajo el gobierno de Raúl Alfonsín. El reconocimiento de los derechos indígenas en los casos de las constituciones «populistas» de Bolivia y Ecuador, o la sanción de leyes que reconocen el matrimonio entre personas del mismo sexo en Argentina son apenas una muestra de políticas tendientes a expandir el alcance de los derechos de sectores excluidos de la comunidad.

Por lo expuesto sostenemos que las críticas a los regímenes tildados de populistas deben incorporar un conocimiento fundado de las dinámicas históricas, políticas y culturales de las naciones que se pretende cuestionar. Es preciso entonces tomar nota de las palabras del propio De la Torre, referencia repetidamente citada por Guariglia: 
«El problema es que muchos críticos del populismo lo ven únicamente como un peligro, descuidando el análisis de sus rasgos democratizadores y que en su afán de frenarlo idealizan las características de las democracias donde surgieron. Es así que muchos críticos del chavismo, del correísmo y del evismo se olvidan que las democracias en las que emergieron estos liderazgos fueron excluyentes y que tuvieron elementos autoritarios. Sin un análisis sobre las ambigüedades del populismo para la democratización sus críticos seguirán construyendo modelos normativos que confunden lo que debe ser la democracia con lo que en realidad ha sido en la región. Además, seguirán utilizando prácticas discursivas decimonónicas para caracterizar a los seguidores de los populistas como masas aún no preparadas para ejercer la democracia. En estos debates pasionales sus apologistas se olvidan de la importancia de preservar y profundizar las libertades y las instituciones que garantizan que la pluralidad de lo social no sea abolida en fantasías autoritarias de la redención del pueblo» (De la Torre, 2009:36).

En otro trabajo, De la Torre insiste también en la tensión que existe en países como Venezuela, Bolivia y Ecuador entre un debilitamiento de las instituciones liberales y un crecimiento de la participación de sectores de la comunidad política que habían sido tradicionalmente excluidos. Con acierto el autor invita a pensar «las características de la participación y deliberación en las instituciones creadas para suplantar o mejorar la democracia liberal en estas naciones»» (2010:46).

Las otras tres referencias empíricas que ofrece el autor tienen como protagonista a la Argentina. Por un lado:

es erróneo dar por supuesta la posesión entre los peor situados de una capacidad para gozar plenamente de su autonomía y estar en condiciones de planear razonablemente sus vidas. Más bien, como la existencia del populismo lo pone de manifiesto, precisamente es la carencia de la posibilidad de desarrollar la propia autonomía en amplias franjas de la población la que fuerza a éstas a agruparse en asociaciones espontáneas para salir de su aislamiento y hacer valer sus demandas. El fenómeno de los «piqueteros » que desde la crisis de 2001 en Argentina ha proliferado, en parte espontáneamente y en parte con apoyo explícito de los gobiernos de los presidentes Néstor y Cristina Kirchner, es un claro ejemplo de ello (Guariglia, 2011:64).

Es preciso notar en la cita la referencia a un punto de partida empírico (el error de suponer capacidad de gozar de autonomía y planear razonablemente sus vidas por parte de los peor situados ${ }^{11}$ ) y la postulación de un mecanismo sociológico: dada esta situación, los peor situados se ven forzados a agruparse espontáneamente, algo que explicaría las movilizaciones protagonizada por los desempleados en Argentina, apoyadas por el gobierno de Néstor y de Cristina Fernández. Ahora bien, los procesos de acción colectiva y la organización de los conocidos como «piqueteros» han ocupado un lugar destacado en la sociología política del país al punto de erigirse como un campo de estudios que lleva más de una década. En tal sentido, los trabajos de Auyero 2002, Svampa y Pereyra, 2003, Manzano 2004, Delamata 2004, Quirós, 2006, por citar solo algunos, demuestran que la experiencia de los movimientos de desocupados y otros sectores que utilizaron la barricada sobre carreteras (o «cortes de ruta/piquete») no pueden considerarse «asociaciones espontáneas» que respondan al irracionalismo o conductas espasmódicas. Por el contrario todos estos estudios muestran que entre la estructura social (permanecer sin empleo) y las acciones de protesta, median un conjunto complejo de procesos (dimensiones culturales, prácticas políticas, activismo militante, experiencias de organización, capital social, repertorios de acción colectiva, entre otros). Es síntesis, la tesis del espontaneismo es refutada por la evidencia em- 
pírica y la sociología política la ha desestimado hace décadas, de hecho la sociología de la acción colectiva surge en parte de este rechazo.

Ahora bien, enfoquémonos en la relación del los desempleados movilizados («piqueteros») y el gobierno «populista» de Néstor Kirchner y actualmente Cristina Fernández de Kirchner. El primer aspecto a tener en cuenta es que el origen del movimiento de desocupados puede ubicarse, según las investigaciones citadas, hacia 1995-1996, fecha en que las primeras organizaciones de desocupados comenzaron a movilizarse para exigir una solución a sus condiciones de vida, fundamentalmente permanecer sin empleo y exentas de cobertura asistencial (seguros, subsidios, pensiones). Es decir en plena hegemonía neoliberal y ocho años antes de la asunción de Néstor Kirchner a la presidencia. El auge de la movilización de los desocupados se sitúa en el ciclo de protesta entre 1999 y 2001 para ir decayendo hacia finales de 2002. El kirchnerismo desde mediados del 2003 incluyó tanto en su discurso como en sus políticas públicas a los sectores desempleados (identificándolos como las principales víctimas del neoliberalismo). En este contexto un conjunto de organizaciones del movimiento de desocupados decidieron incorporarse al proyecto político que gobierna actualmente a la Argentina proveyendo cuadros políticos para le gestión y protagonizando movilizaciones a favor de las políticas del gobierno nacional. ${ }^{12}$

La segunda referencia más elíptica a la Argentina la encontramos precisamente en relación a los resultados de los indicadores sociales bajo gobiernos populistas:

«Aún concediendo que el populismo podría promover una mejor distribución de los recursos a favor de los peor situados —una pretensión que contradice empero los datos empíricos (véase Gargarella y Lo Vuolo, 2009)_, existe un campo de la vida social y política de la democracia en la que esa supuesta superior justicia distributiva no solamente es inexistente sino que se trasforma en su extremo opuesto: la distribución de los derechos y las oportunidades políticas entre los ciudadanos de una sociedad desigual» (Guarigla, 2011:67).

Cabe destacar que la mencionada evidencia empírica no existe en el trabajo de Roberto Gargarella y Rubén Lo Vuolo (2009), que consiste en una columna de opinión sobre el caso argentino compuesta por seis párrafos publicado en el diario Clarín en la que no se consigna ningún tipo de datos. Esto no significa que no existan investigaciones sobre los alcances y límites de las políticas implementadas desde el 2003 en Argentina y en el resto de América Latina. En especial, el desempeño en variables socioeconómicas del gobierno argentino desde 2003 a la actualidad ha sido objeto de profundos y rigurosos debates. En varios trabajos se aporta evidencia empírica sólida sobre el descenso de la desocupación y la pobreza, además de la reducción de la desigualdad medido por el coeficiente de Gini. Trabajos editados no en diarios de línea editorial adversa al gobierno argentino sino en publicaciones avaladas por el Programa para el Desarrollo de Naciones Unidas, la OIT y la CEPAL $^{13}$ deberían ser consultados al respecto. (Bertranou, coord., 2010, Trujillo y Villafañe, 2011).

Finalmente encontramos las siguientes palabras,

«Por el contrario, como ha sido ya señalado por la crítica académica, los gobiernos neopopulistas se han inclinado hacia un autoritarismo creciente, para el que toda crítica de los medios no debe ser tolerada sino en lo posible ahogada en su mismo origen. (De la Torre, 2009, 30-33; O’Donnell, 2010) 
Sin embargo, nada dice entre las páginas 30-33 De la Torre sobre la relación de los líderes andinos con respecto a la crítica de los medios, se limita a afirmar «Los técnicos en manipulación mediática ocupan posiciones claves en estos gobiernos y hacen un uso extensivo de los sondeos de opinión pública y de otras técnicas comerciales para incrementar la popularidad de los mandatarios que tienen protagonismo y presencia en los medios» (De la Torre, 2009:30), algo que puede considerarse como una marca de las campañas políticas contemporáneas en el marco de la mediatización de la política y no necesariamente vinculado al populismo. Ahora bien, veamos qué recupera del artículo que toma de Guillermo O'Donnell ${ }^{14}$ Nuevamente aquí se apoya en un artículo publicado en el diario Clarín, donde el autor retoma su conocida concepción de democracia delegativa. Allí aclara explícitamente que «La versión "delegativa” es democrática porque resulta de elecciones razonablemente limpias y porque (aunque con la salvedad del riesgo de deslizamiento autoritario) respeta libertades básicas, tales como las de expresión, asociación y prensa». En ningún momento O'Donnell toca en ese texto el tema del supuesto «ahogo» de las críticas en su mismo origen.

Podemos mencionar dos aspectos importantes para la relación del gobierno de Kirchner con la prensa que va en sentido contrario de la afirmación citada. Por un lado el acompañamiento de los diputados del Frente para la Victoria del proyecto que derogó del Código Penal los delitos contra el honor bajo las figuras de calumnias e injurias, siguiendo las observaciones de la Corte Interamericana de Derechos Humanos, la Relatoría para la Libertad de Expresión de la Comisión Interamericana de Derechos $\mathrm{Hu}-$ manos y diversas organizaciones no gu- bernamentales. Parece a todas luces inexplicable que un gobierno que busca acallar a la prensa se autoimponga limitaciones para judicializar opiniones vertidas en medios de comunicación. El otro punto significativo de la relación de este gobierno «populista» con los medios es la derogación de la ley que regula la comunicación audiovisual sancionada por la última dictadura militar (1976-1983) y su reemplazo por la Ley de Servicios de Comunicación Audiovisuales, luego de meses de debate ciudadano a partir de la producción de foros «deliberativos» en los que diferentes actores (organizaciones no gubernamentales, académicos, periodistas, empresarios del sector mediático, cooperativas, sindicatos) participaron en el tratamiento del proyecto de la Ley. El Relator para la Libertad de Expresión de la ONU Frank La Rue calificó a la Ley como «lo más avanzado que he visto en el continente» (Página 12 15-07-2009) y la incluyó como un aporte relevante en el Segundo Informe ante la Asamblea General de la ONU en Junio de 2010. ${ }^{15}$

Por supuesto que esto no implica la ausencia de tensiones entre los gobiernos de la región y la «prensa», ${ }^{16}$ sin embargo no se puede soslayar que la propiedad de los medios de información está concentrada en oligopolios que constituyen el espacio público mediático, mercantilizan la información e influyen en la formación de opinión pública. Estos conflictos deben ser comprendidos en su dimensión histórica y política, así como la necesidad de contar con un espacio público con ciertos atributos para favorecer la formación de una opinión pública crítica. Difícilmente Habermas pueda ser acusado de populista. La posición dominante de las corporaciones mediáticas en América Latina no es un dato a desdeñar y ayuda a comprender los conflictos de los gobiernos «populistas» con las grandes cor- 
poraciones que entre otras empresas poseen medios de comunicación (Kitzberger, 2009).

\section{Al final: ¿otra vez populismo y la democracia?}

Para concluir quisiéramos volver sobre lo que es quizás la tesis central del artículo aquí discutido: ante las promesas incumplidas de la democracia en América Latina la democracia deliberativa es una alternativa deseable al populismo. Como podemos inferir de lo expuesto, si la raíz de la propuesta de Guariglia es demostrar que el concepto normativo de democracia deliberativa es superior al de populismo, tal objetivo no se consigue porque no se confronta su concepto normativo con otro concepto normativo (democracia participativa, comunitaria, popular, etc.) propio del «populismo» ${ }^{17}$ que podría estar planteado en la idea de «socialismo siglo XXI» (Venezuela), «revolución ciudadana» (Ecuador) o los trabajos del propio vice-presidente de Bolivia, Álvaro García Linera (entre cuyos textos se encuentra un titulado sugerentemente «Democracia liberal vs. Democracia comunitaria», 2004). Esto posicionaría al debate como un rico terreno en donde emergen posturas críticas a la visión liberal-representativa de la democracia y el giro individualista efectuado por Grocio y sobre el que se erige el liberalismo político. De hecho gran parte de los pensadores latinoamericanos como Edgardo Lander (2000), Santiago Castro (2000), Aníbal Quijano (2002) y Walter Mignolo (2008) han cuestionado al pensamiento colonial que asume elementos de la tradición liberal-eurocéntrica-occidental-moderna y los instituye como raseros para medir el nivel de «atraso» de las democracias de la región en comparación con los países del norte. ${ }^{18}$ Otros autores como León Olivé (2003), Am- brosio Velasco (2006) y Enrique Dussel (2007) han ofrecido miradas sobre la realidad latinoamericana que integran críticamente las tradiciones de la filosofía occidental con los contextos históricos, políticos y culturales. La extensión del ideal de democracia deliberativa hacia países de América Latina como Bolivia, Ecuador, Perú y México por ejemplo exige dar cuenta de la pluralidad de racionalidades, cosmovisiones y ethos, de lo contrario corremos el riesgo de una nueva conquista mediante la imposición de una racionalidad occidental y moderna a las comunidades indígenas y demás sectores subalternos. ${ }^{19}$

La elección de la teoría del populismo de Ernesto Laclau como adversario dialéctico no logra aportes fructíferos porque dicha teoría no contiene desarrollada una concepción normativa de democracia (la cual en todo caso hay que buscar en su teoría de la democracia radical). La categoría de populismo que elabora Laclau tiene fundamentalmente una función analítica, es decir, sirve para estudiar dinámicas políticas presentes en distintos contextos. Es cierto que Laclau (2006) ve con simpatía a los llamados populismos latinoamericanos (Argentina, Ecuador, Venezuela y Bolivia), pero no porque éstos sean populismos sino por los efectos políticos (en tanto tramitación e incorporación de demandas excluidas de sectores subalternos) que las articulaciones populistas han logrado en estos países y que no pudieron ser canalizadas mediante otras lógicas políticas. En todo caso es lícito requerir de Laclau una mayor precisión sobre su concepción de democracia y política radical, así como discutir los efectos políticos de los procesos boliviano, ecuatoriano, venezolano y argentino recientes en cuanto a su capacidad de incluir a sectores previamente excluidos, redistribución de la ri- 
queza, reconocimientos a los derechos de las minorías y culturas indígenas.

La posición de Chantal Mouffe es significativamente diferente a la de Laclau en este aspecto y muy próxima a la que parece defender Guariglia. Dice Mouffe: «Al igual que los defensores del "liberalismo político" también quisiera ser testigo de la creación de un amplio consenso en torno a los principios de la democracia pluralista» y luego marca la diferencia con el planteo que sigue Guariglia: «Pero no creo que tal consenso debiera estar basado en la racionalidad y la unanimidad que debería manifestar un punto de vista imparcial» (Mouffe, 1993: 205). Lo que la autora argumenta es la imposibilidad de considerar a los valores liberales como universales y últimos (incluso trascendentes, naturales o innatos) y la necesidad de crear identificaciones con esos valores por parte de los diferentes sectores de la polis precisamente como modo de resguardar y ampliar la democracia liberal. En palabras de Mouffe: «lo que propongo es que la adhesión a los principios políticos del régimen democrático liberal sean la base de la homogeneidad que la igualdad democrática requiere. Los principios en cuestión son libertad e igualdad y es evidente que pueden dar origen a múltiples interpretaciones y que nadie puede pretender poseer la interpretación "correcta". En consecuencia, es esencial establecer cierto número de mecanismos y procedimientos para tomar decisiones y para determinar la voluntad del Estado en el marco de un debate sobre la interpretación de estos principios» (Mouffe, 1993:177). Mouffe es una crítica del liberalismo rawlsiano y de la propuesta habermasiana pero difícilmente se pueda acusar a su propuesta de democracia radical y plural «agonal» (2007) de una apología del «populismo autoritario».
Ahora bien, si lo que el artículo ofrece es una crítica al desempeño de los gobiernos tildados como populistas en el campo de la democracia es acertado que se defina lo que se entiende por democracia y se asuma una dimensión normativa (en este caso una lectura de Aristóteles y una posición deliberativa que puede ser discutida) y luego se demuestre empíricamente que los gobiernos tienden sistemáticamente a subvertir estos patrones. Allí pueden detectarse dos aspectos relacionados. El escaso desarrollo de los debates en torno a la democracia deliberativa y sus condiciones de posibilidad en América Latina (para defender la tesis enunciada «que la democracia deliberativa es una respuesta superior a esas promesas» (Guariglia, 2011:58). Pero también la debilidad de las fuentes y evidencias convocadas para caracterizar como autoritarias las respuestas populistas a las promesas incumplidas de la democracia. En síntesis, la evidencia ofrecida sobre el funcionamiento de los gobiernos llamados populistas dista mucho de ser concluyente y se utilizan como recursos retóricos para construir un «Monstruo» ${ }^{20}$, para usar la figura borgeana, cuya sola presencia invoca solo rasgos autoritarios al que hay que oponerle formas liberales de democracia. No pretendemos aquí aportar evidencia concluyente para sostener la tesis contraria sino simplemente sugerir que para sustentar el argumento tal como está construido se requiere de precisión en el uso de las fuentes.

El artículo de Guariglia introduce problemas clásicos de la filosofía política e incentiva a seguir trabajando críticamente sobre los procesos actuales y, en consecuencia, es un gran aporte para el debate sobre el populismo. Por un lado nos alienta a revisitar controversias clásicas sobre la democracia (que evocan muchas de sus longevas preguntas) pero 
que deben incorporar perspectivas contemporáneas, el aporte de los filósofos, sociólogos y antropólogos latinoamericanos es fundamental para pensar la región porque ayudan a incluir aspectos como la diversidad cultural, étnica, las cosmovisiones originarias desde un pensamiento situado. El segundo aspecto que el artículo que estamos comentando deja abierto es el estudio de los efectos históricos (democratizadores y/o autoritarios) de los populismos. ${ }^{21}$

Lejos de presentarlos como dimensiones aisladas ambos son dos caras de la misma moneda. La filosofía deshistorizada puede conducir al ejercicio de reflexiones morales (filosofía sin política) desde lugares que olvidan los contextos culturales, políticos, económicos y sociales que hacen a la materialidad de la polis sobre la cual presuntamente predican. Difícilmente encontremos entre los grandes filósofos occidentales semejante yerro. Platón y Aristóteles pensaron la crisis de la Atenas del siglo IV a.c., Maquiavelo el Renacimiento tardío y la organización italiana, Hobbes el advenimiento del Commonwealth, Hegel escribía viendo entrar las tropas napoleónicas a Jena en 1806, Marx en las consecuencias de la revolución industrial en Europa y las insurrecciones de 1848 y 1871 . Nosotros - los latinoamericanos - desde la América Latina (pos)neoliberal y (pos)colonial. Desde este punto de partida emergen preguntas sobre las concepciones de democracia que subyacen a estos proyectos políticos, su relación con las tradiciones (liberales, republicanas, socialistas), los arreglos institucionales que propusieron para consolidarlas y los alcances concretos (resultados y dificultades) de las experiencias.

La dimensión normativa y el análisis histórico encuentran un punto de convergencia cuando nos preguntamos por las condiciones de posibilidad de la demo- cracia deseable o de una democratización de la democracia a partir de las situaciones actuales de los países de América Latina. En este horizonte es lícito preguntarnos: ¿Qué fuerza política propondrá las «reformas deliberativas»?.. ${ }^{22}$ El desacuerdo en este punto es metodológico. La otra mirada implica partir de la situación histórico-concreta en la que emergieron los procesos actuales tildados de populismo: grandes desigualdades sociales, exclusiones en la participación y negaciones de las identidades culturales y, como reconoce Guariglia «Desigualdad implica sujeción, pérdida relativa de independencia, carencia de capacidades y de oportunidades, ausencia de fines y, por último, anihilamiento de la propia autonomía» (2011:65). De allí la posibilidad de instaurar un régimen político más inclusivo no radica en juegos de diseño normativo sino que supone constitución de sujetos políticos (ciudadanías) capaces de ejercer su soberanía. ${ }^{23}$ El populismo en la versión de Laclau ayuda a comprender esta gramática aunque nada diga a priori de los contenidos ni de los resultados. El espectro del populismo, como una lógica política, ofrece la posibilidad de politizar aquellos aspectos que han quedado fuera del ámbito público del debate. Los efectos democratizadores (más allá de la democracia liberal) del populismo, sus derivas autoritarias, así como su relación con elementos de la democracia deliberativa y la puesta en práctica de arreglos institucionales en esta perspectiva, es un tema imperioso de futuras investigaciones y debates. El diálogo está abierto; lo celebramos.

\section{BIBLIOGRAFÍA}

Aboy Carlés, G. (2005): «Populismo y democracia en la Argentina contempo- 
ránea. Entre el hegemonismo y la refundación». Estudios sociales, 15(27).

Aboy Carlés, G. (2010): «Populismo, regeneracionismo y democracia». POSTData: Revista de Reflexión y Análisis Político, 15(1), 11-30.

Agis, E., Cañete, Carlos. y Panigo, D. (2010): «El impacto de la asignación universal por hijo en Argentina», Documento de trabajo CEIL-PIETTECONICET, Argentina.

Aibar Gaete, J. (2007): «La miopía del procedimentalismo y la presentación populista del daño». Vox populi: populismo y democracia en Latinoamérica (Vol. 1, p. 19). México: FLACSO.

Aibar, J., \& Avaro, D. (2006): «Instituciones y movilización popular: una difícil pero necesaria combinación»». Entrevista con Ernesto Laclau. Revista internacional de filosofía política, (28), 191-196.

Aibar, J., \& Vázquez, D. (2009): ¿Autoritarismo o democracia?: Hugo Chávez y Evo Morales. México: FLACSO México.

Apel, K.-O., \& Dussel, E. D. (2005): Ética del discurso y ética de la liberación. Madrid: Trotta.

Arditi, B. (2004): «Populism as a spectre of democracy: a response to Canovan». Political Studies, 52(1), 135-143.

Arditi, B. (2009): El Giro a la Izquierda en América Latina: ¿Una política pos liberal? en Ciências Sociais Unisinos.

Auyero, J. (2002): La protesta: retratos de la beligerancia popular en la Argentina democrática. Buenos Aires: UBA.

Barros, S. (2006): «Inclusión radical y conflicto en la constitución del pueblo populista». CONfines de relaciones internacionales y ciencia política, (3), 4.

Bertranou, Fabio. (Coord.) (2010): Aportes para la construcción de un piso de protección social en Argentina: El caso de las asignaciones familiares.
Buenos Aires, Oficina de la OIT en Argentina.

Borges, J. L. Borges, Obras Completas, 18 ed., Emecé Editores, T. III, Buenos Aires.

Canovan, M. (1999): «Trust the people! Populism and the two faces of democracy». Political studies, 47(1), 2-16.

Castañeda, Jorge (2006): «Latin America's Left Turn», Foreign Affairs, 85 (3): 28-43.

Critchley, S. (2008): «¿Hay un déficit normativo en la teoría de la hegemonía?» en Critchley \& Marchart. Laclau. Aproximaciones críticas a su obra (pp. 145-146). Buenos Aires: FCE.

De la Torre, Carlos. (2009): «Populismo radical y democracia en los Andes», Journal of Democracy en Español, I, 24-37, accesible en: http:/www.journalofdemocracyenespanol.cl/pdf/delatorre.pdf, volumen 1, julio.

De la Torre, Carlos (2010): «¿Más allá de la democracia representativa procedimental?» en Ecuador Debate (80), pp. 45-72.

Delamata, G. (2004): Los barrios desbordados: las organizaciones de desocupados del Gran Buenos Aires. Editorial Universitaria de Buenos Aires. EUDEBA.

Dussel, E. (2007): Política de la liberación: historia mundial y crítica. Madrid: Editorial Trotta.

Dussel, E. (1996): «La ética de la liberación ante la ética del discurso». Isegoría, (13), 135-149.

Dussel, E. (2006): 20 tesis de política. México: Siglo XXI Ediciones.

Lander, E (2000): Ciencias sociales: saberes coloniales y eurocéntrico. En La colonialidad del saber: eurocentrismo y ciencias sociales. Perspectivas latinoamericanas. Edgardo Lander. CLACSO, Buenos Aires, Argentina. Julio. 2000: http://bibliotecavirtual. 
clacso.org.ar/ar/libros/lander/lander1. rtf.

Elster, J. (comp.). (2001): La democracia deliberativa. Barcelona: Gedisa.

García Linera, Á. (2004): «Democracia liberal versus democracia comunitaria». El Juguete Rabioso, 3(96).

Gasparini, L y Cruces G (2010): Las Asignaciones Universales por Hijo: impacto, discusión y alternativas. Documento de Trabajo Número 102, CEDLAS-UNLP.

Guariglia, O. (2011): «La Democracia en América Latina: la alternativa entre populismo y democracia deliberativa». Isegoría, (44), 57-72.

Ionescu, G., \& Gellner, E. eds. (1969): Populism: its meaning and national characteristics. London: Weidenfeld and Nicolson.

Kitzberger, Philip. Las relaciones gobierno-prensa y el giro político en América Latina. Postdata [online]. 2009, vol.14, n.2 [citado 2011-12-12], pp. 157-181. Disponible en: <http:// www.scielo.org.ar/scielo.php? script $=$ sci_arttext\&pid $=\mathrm{S} 1851$ $96012009000200003 \& \operatorname{lng}=\mathrm{es} \& \mathrm{nrm}=\mathrm{i}$ so>. ISSN 1851-9601.

Laclau, E. (2005): On populist reason. London: Verso Books.

Laclau, E. (2006): «La deriva populista y la centroizquierda latinoamericana». Nueva sociedad, (205), 56-61.

Laclau, E. (2009): «Populismo: ¿qué nos dice el nombre?» En El populismo como espejo de la democracia. Panizza (comp.) (pp. 51-70). Buenos Aires: FCE.

Mackinnon M. y Perrone. A (Comp) (1996): Populismo y neopopulismo en América Latina. El problema de la Cenicienta. Introducción, Bs.As, Eudeba, 1996.

Mignolo, W. (2008): «Hermenéutica de la democracia: el pensamiento de los límites y la diferencia colonial». $T a-$ bula Rasa, (9), 39-60.

Olive, L. (2003): «Un modelo multiculturalista más all'a de la tolerancia». Diánoia, 48(51), 83-96.

Quijano, A. Colonialidad del poder, globalización y democracia Trayectorias [en línea] 2002, 4 (septiembre-abril): [fecha de consulta: 12 de diciembre de 2011] Disponible en: <http://redalyc.uaemex mx/redalyc/src/inicio/ ArtPdfRed.jsp?iCve $=60700805>$ ISSN 1405-8928.

Quirós, J. (2006): Cruzando la Sarmiento: Una etnografía sobre piqueteros en la trama social del sur del Gran Buenos Aires. Buenos Aires: Antropofagia.

Solodkow, D. (2005): «Racismo y Nación». Decimonónica, 2(1), 95-121.

Svampa, M. S. (1994): Civilización o Barbarie: el dilema argentino, de Sarmiento al revisionismo. Buenos Aires: El cielo por asalto.

Svampa, M., \& Pereyra, S. (2003): Entre la ruta y el barrio: la experiencia de las organizaciones piqueteras. Buenos Aires: Editorial Biblos.

Trejo, Raúl (2010): «Muchos medios en pocas manos: concentración televisiva y democracia en América Latina» Intercom-Revista Brasileira de Ciências da Comunicação 18 São Paulo, v.33, n.1, p. 17-51, jan./jun. 2010.

Trujillo, L. y Villafañe, S. (2011): Dinámica Distributiva y Políticas Públicas: Dos décadas de contrastes en La Argentina contemporánea. En: Distribución del ingreso. Enfoques y políticas desde el sur. PNUD-MTEySSl. Argentina.

Velasco Gómez, A. (2006): Republicanismo y multiculturalismo. Siglo XXI.

Weyland K. (2003): «Neopopulism and Neoliberalism in Latin America: how much affinity?» Third World Quarterly, Vol 24, No 6, pp. 1095-1115. 
Weyland, K, De la Torre, Aboy Carlés, F \& Ibarra, C (2004): Releer los populismos, CAAP: Quito.

Weyland, Kurt (2001): «Clarifying a Contested Concept: Populism in the Study of Latin American Politics».
Comparative Politics, Vol. 34, No. 1

(Oct., 2001), pp. 1-22.

Zea, Leopoldo. «El proyecto de Sarmiento y su vigencia», Cuadernos Americanos, 13.1 (1989): 85-96.
${ }^{1}$ La antinomia se esfuma al deconstruir las condiciones de posibilidad del planteo antitético.

${ }^{2}$ Los trabajos de Gerardo Aboy Carlés (2005 y 2010) y Sebastián Barros (2006) se inscriben en esta perspectiva.

${ }^{3}$ En general la literatura sobre populismo indica su origen en los narodnichestevo (Ionescu y Gellner, 1969), y luego la extensión del uso en referencia a los populismos agrarios. En América Latina el término se utilizó inicialmente para designar gobiernos como los de Lázaro Cárdenas (México), Getúlio Vargas (Brasil), Juan D. Perón (Argentina), conocidos «populismos clásicos». El término regresó con el prefijo «neo» para designar a gobiernos que introdujeron reformas neoliberales hacia la década del noventa: Alberto Fujimori (Perú), Carlos Menem (Argentina), Abdalá Bucarám (Ecuador), Collor de Melo (Brasil) (Mackinnon y Perrone, 1996; Weyland, 2003, et. al.) y finalmente un debate sobre el uso de populismo se reactivó para designar gobiernos con políticas y discursos «anti neoliberales» como Hugo Chávez, Néstor Kirchner, Evo Morales, Rafael Correa (Aibar y Vázquez, 2009).

${ }^{4}$ No obstante es preciso advertir que el artículo deja de lado muchas de los debates en torno a la noción de democracia(s) deliberativa(s) y sus alcances, al respecto puede consultarse, entre otras, la compilación de Jon Elster (2001).

${ }^{5}$ En tal sentido si populismo se define como un liderazgo personalista, decisionista y autoritario que construye un régimen que no respeta las libertades de los ciudadanos entonces no hay mucho lugar para ensayar una defensa del populismo. Aibar (2007) sintetizó las críticas que desde el pensamiento liberal se han realizado hacia el populismo calificándolas como «las miopías del procedimentalismo».

${ }^{6}$ El desempeño de los gobiernos en América del Sur, tanto en los casos identificados como populistas (Bolivia, Ecuador, Venezuela, Argentina), como en los de la izquierda moderada (Brasil, Uruguay, Paraguay hasta la caída de Fernando Lugo) debe ser objeto de estudios multidisciplinarios capaces de indagar en avances y limitaciones de estos gobiernos para fortalecer la ciudadanía y la democracia (que por supuesto no es independiente de las concepciones normativas en juego y de las definiciones operativas que hacen a lo metodológico de los estudios), así como los efectos de las políticas de combate a la pobreza y la desigualdad.

${ }^{7} \mathrm{La}$ idea de «los de abajo» (la plebe) ha generado confusiones cuando por un lado se la asocia sectores de las clases subalternas pero por otro la teoría del populismo concibe que puede existir un populismo de los sectores dominantes. Lo cierto es que en cualquier caso el punto de partida es la existencia de demandas insatisfechas de un sector de la sociedad.

${ }^{8}$ No deja de resultar llamativo que se predique sobre «las democracias de América Latina» (2011:57) cuando se toman cuatro países de América del Sur.

${ }^{9}$ Aquella autonomía que la democracia requiere es definida por Kirk Hawkins y David Hansen (De la Torre, 2009).

${ }^{10}$ Ver artículos 204 a 210.

11 También es preciso reparar en que el argumento predica una falta de capacidad para el goce de la autonomía y no de oportunidades de los «peor situados».

${ }^{12}$ El gobierno argentino implementó desde 2003 políticas tendientes a reconstruir el mercado de trabajo y destinó políticas de transferencias de ingresos, la última de las cuales la «Asignación Universal por Hijo» fue pensada como derecho ciudadano que evita cualquier tipo de intermediario, jaqueando de este modo las acusaciones de «clientelismo» que frecuentemente se vierten sobre los gobiernos «populistas». Los efectos redistributivos y en la ciudadanía han sido estudiados por especialistas desde diferentes paradigmas y preocupaciones. Estudios tanto desde enfoques ortodoxos (Gasparini y Cruces, 2010) como heterodoxos (Angis, Cañete y Panigo, 2010) que incluyen metodologías econométricas han analizado el impacto de esta política pública en la sociedad argentina.

${ }^{13}$ En el informe 2011 de la CEPAL se consigna que Argentina y Venezuela, bajo gobiernos tildados de populistas, redujeron la pobreza en 36,8 y 20,8 puntos porcentuales respectivamente entre 2002 y 2010 . http //www.eclac.cl/publicaciones/xml/1/45171/ CAPITULO_I_no_editado.pdf. Según el mismo informe en Ecuador en 2002, el $49 \%$ de la población era pobre, luego en 2009 disminuyó al 40\% y en 2010 al $37 \%$. Aun así toda mirada economicista de los efectos políticos en estos países es sesgada ¿cómo puede medirse el reconocimiento constitucional de una cultura 
subalternizada y estigmatizada por más de cinco siglos?

${ }^{14}$ Guillermo O'Donnell tiene otros trabajos académicos en los que defiende desde una perspectiva liberal la necesidad de una democracia como poliarquía, ampliando los requisitos de la fórmula de Robert Dahl.

${ }^{15}$ El documento puede consultarse en: http //censuraindirecta.org/web files/download/publicaciones/ archivo/Informe-Relator-ONU junio2010-pdf-1612. $p d f$ (visitado el 29 de noviembre de 2011).

${ }^{16}$ Un trabajo actualizado sobre concentración mediática en América Latina: Trejo 2010.

${ }^{17}$ Recordemos que una de las posibles críticas a los gobiernos llamados populistas radica en la falta de elaboración o desarrollo de un concepto normativo de democracia que guíe sus acciones.

${ }_{18}$ Muchas de estas controversias alcanzan al artículo de Guariglia, los tropos y giros que funcionan como «operadores coloniales» entre los que podemos mencionar «usual retraso de medio siglo» (p.63) y la curiosa referencia a Domingo F. Sarmiento, quien como se sabe propuso reemplazar la población indígena y criolla por inmigrantes europeos (anglosajones) dada la natural incapacidad de los habitantes de América Latina para la civilización y la modernidad son muestra de ello (Zea, 1989, Svampa, 1994; Solodkow, 2005). Lamentablemente no podemos dedicar espacio aquí al análisis de las visiones de la democracia noeurocéntricas y críticas de la modernidad capitalista, no obstante sirven como alerta de las otras concepciones de democracia que son tramitadas en los debates políticos latinoamericanos y que entran en tensión (o se articulan) con las formas occidentales de la democracia (la cual también es una de las tradiciones constitutivas de América Latina).

${ }^{19}$ En Bolivia por ejemplo se reconocen como idiomas oficiales, en el artículo 5 de la Constitución: «el castellano y todos los idiomas de las naciones y pueblos indígena originario campesinos, que son el aymara, araona, baure, bésiro, canichana, cavineño, cayubaba, chácobo, chimán, ese ejja, guaraní, guarasuawe, guarayu, itonama, leco, machajuyai-kallawaya, machineri, maropa, mojeño-trinitario, mojeño-ignaciano, moré, mosetén, movima, pacawara, puquina, quechua, sirionó, tacana, tapiete, toromona, uruchipaya, weenhayek, yaminawa, yuki, yuracaré y zamuco», esto no es solo un problema idiomático, sino que afecta las condiciones de razonabilidad y estructura de los argumento, el ethos común de referencia., etc. Filósofos como Enrique Dussel han dedicado obras completas a discutir los alcances democráticos de las experiencias referidas como populistas y propuesto discusiones desde perspectivas críticas a las concepciones liberales y «dialógicas» (Apel y Dussel, 2005).

${ }^{20} \mathrm{~J}$ L. Borges y A. Bioy Casares escribieron un cuento llamado «La Fiesta del Monstruo» en alusión a las movilizaciones obreras en el primer peronismo (1946-1955).

${ }^{21}$ Sobre el tema ya existe una bibliografía considerable, entre ellos: «¿Autoritarismo o democracia? Hugo Chávez y Evo Morales. FLACSO-México, 2010, compilado por Julio Aibar y Daniel Vázquez.

${ }_{22}$ Imaginariamente esta posibilidad supondría que se de alguna de las siguientes alternativas: a) la invasión por parte de países «avanzados» para llevar la igualdad y la libertad (como los principios aristotéli$\cos$ ), b) que las elites dominantes tras décadas en el poder decidan instalar una democracia deliberativa debido a su rigor moral, c) que partidos socialdemócratas con programas deliberativos se constituyan, alcancen mayorías electorales y lleguen al poder, d) que los movimientos populares actuales contengan en sus programas propuestas de instancias de deliberación, publicidad de los debates parlamentarios, derecho a la información como instituciones democráticas. El populismo, tal como lo concibe Laclau es una lógica, en tal sentido podemos pensar que articule las demandas de instaurar espacios públicos de deliberación, transparencia en los debates parlamentarios, etc. «Democracia (deliberativa)» puede funcionar como un significante vacío para aglutinar individuos y grupos con demandas de democracia en este sentido, solo que para ello se requeriría de la intervención de una lógica populista.

${ }^{23}$ La relación de la democracia con la soberanía y el poder constituyente es un tema de suma relevancia para la política en América Latina y soslayado en el artículo. 